УДК 159.9-016-22 -63- 64.22 -64.26-72-8: 615.851

Григорьева Светлана Викторовна, доктор философии в области медицинской психологии, психотерапевт, заместитель руководителя секции психоанализа, специалист психоаналитической психотерапии, детский психотерапевт; Центр семейной нейрокоррекции и психотерапии «Таламусвита», 65000, ул. Спиридоновская, 18/24, г. Одесса, Украина; svetart501@gmail.com; +38(067) 609-46-09

ORCID ID 0000-0003-3405-9521

\title{
ИССЛЕДОВАНИЕ АСИММЕТРИИ МОЗГА И ВЗАИМОДЕЙСТВИЕ СТРУКТУР МОЗГА В ДИАДЕ «МАМА-РЕБЕНОК».
}

\begin{abstract}
Анотація
Григор'сва С. В., доктор філософії в галузі медичної психології, психотерапевт, заступник керівника секції психоаналізу, фахівець психоаналітичної психотерапії, дитячий психотерапевт; Центр сімейної нейрокорекції та психотерапії, м. Одеса, Україна. Дослідження асиметрії мозку та взаємодія структур мозку в діаді «мати-дитина».

Ключові слова: діада «мати-дитина», асиметрія зі співвіднесенням латеральності, прихильність, функціональна спеціалізація півкуль, зорові горби, $\alpha$-ритм, післяродовий стрес, патологія розвитку, позна асиметрія.

Постановка проблеми. Дослідження асиметрії мозку в діаді «матидитина» в рамках теорії прихильності є необхідними та актуальними, тому що для розвитку дитини перший триместр є морфо-створюючим.

Актуальність дослідження. Відповідність або невідповідність параметрів асиметрії мозкових структур учасників взаємодії $є$ важливим
\end{abstract}


фактором у взаєморозумінні між людьми. Нас цікавила наявність зв'язку між різними асиметричними мозковими елементами в діаді «мати-дитина», і як розподіляються ці параметри (латеральність) у парі «дитина-мати».

Аналіз останніх досліджень та публікацій. Дослідники моделі прив'язаності «мати-дитина» приділяють значну увагу міміці матері як одному 3 основних об’єктів, що формують систему «мозок-тіло» немовляти. Пошук близькості відбувається через візуальний контакт 3 матір'ю, але особливо шляхом слідування за матір'ю і встановлення тілесного контакту з нею.

Формулювання мети статті. Мета нашого дослідження - визначити роль асиметрії мозкових структур матері та дитини в формуванні патологічної або нормальної прихильності.

Викладення основного матеріалу. В дослідженні вивчалися латеральні показники позної асиметрії мозку 312 підлітків та їхніх матерів. Для дослідження використовували 4 показники латерального профілю: переплетення пальців рук, схрещення рук на грудях («поза Наполеона»), прицілювання (виявлення домінантного ока) та аплодування (знаходження активної руки).

Дослідження показали, що в нашій вибірці мати 3 дитиною мають достовірну зворотну залежність в очних буграх. Оскільки $\alpha$-ритм у немовлят відсутній, і враховуючи дані, отримані нами, про зв'язок між мамою і дитиною в зоні очних бугрів, можна припустити, що дитина несвідомо підлаштовує свій таламічний водій $\alpha$-ритму під материнський $\alpha$-ритм, компенсаторно орієнтучись на підтримку сенсорних імпульсів матері, таким чином формується спів-стояння пари «мати-немовля». В дітей із патологією зору контакт із матір'ю відбувається через сомато-сенсорні шляхи, які також замикаються в таламусі. Виходячи 3 цього, ми можемо припустити, що в перші три місяці відбувається налаштування взаємодії немовляти з матір’ю не стільки через ії погляд і міміку, 
скільки через деяке резонансне спів-налаштування мозку дитини 3 мозком матері через посередництво $\alpha$ - ритму. Цей період можна назвати «четвертим триместром вагітності».

Висновки та перспективи подальших досліджень. Визначення ведучого ока в матерів та їхніх дітей показало значиму негативну кореляцію, що підтверджує різницю в латералізації, локалізованій у таламусі, де розташовані «очні бугри». Дитина несвідомо підлаштовує свій таламічний водій $\alpha$-ритму під материнський $\alpha-$ ритм, компенсаторно орієнтуючись на підтримку сенсорних імпульсів матері. Вірогідно, в стані стійкої реакції гіперактивності кори ((hyperarousal), «лівопівкульна» мати, щоб заглушити тривогу, може повністю «вимкнути» сигнали (прохання про допомогу), що надсилає ӥй $\dddot{1}$ «правопівкульна» дитина. Тим самим вона, намагаючись від’єднати передачу «небезпечної» інформації, що не відповідає іï стилю мислення, спричиняє дефіцити в розвитку дитини. Невідповідність функціональної асиметрії мозкових структур учасників взаємодії пари «мати-дитина», в разі зрілої особистості матері, створює «нормальну» прихильність через анатомічний i психологічний баланс.

Таким чином, конфлікт різних стилів мислення матері й дитини закладений на глибинному рівні, що може бути однією з умов забезпечення еволюційного розвитку людини.

\section{Аннотация}

Григорьева С. В., доктор философии в области медицинской психологии, психотерапевт, заместитель руководителя секции психоанализа, специалист психоаналитической психотерапии, детский психотерапевт» Центр семейной нейрокоррекции и психотерапии, г. Одесса, Украина. Исследование 
асимметрии мозга и взаимодействие структур мозга в диаде «матьребенок».

Ключевые слова: диада «мать-ребенок», асимметрия с соотнесением латеральности, привязанность, функциональная специализация полушарий, зрительные бугры, $\alpha$-ритм, послеродовый стресс, патология развития, позная асимметрия.

Постановка проблемы. Исследование асимметрии мозга в диаде «матьребенок» в рамках теории привязанности являются необходимыми и актуальными, поскольку для развития ребенка первый триместр является морфо-образующим.

Актуальность исследования. Совпадение или несовпадение параметров асимметрии мозговых структур участников взаимодействия является важным фактором во взаимопонимании между людьми. Нас интересовало, существует ли связь между параметрами асимметрии мозговых структур в диаде «матьребенок», и как распределяются эти параметры (латеральность) в паре «ребенок-мать».

Анализ последних исследований и публикаций. Исследователи моделей привязанности «мать-ребенок» уделяют большое внимания мимике матери как одному из основных объектов, формирующих систему «мозг-тело» младенца. Поиск близости происходит через визуальный контакт с матерью, но особенно путем следования за матерью и установления телесного контакта с ней.

Формулировка цели статьи. Цель исследования - определить роль асимметрии мозговых структур мамы и ребенка в формировании патологической или нормальной привязанности.

Изложение основного материала. В исследовании изучались латеральные показатели позной асимметрии мозга 312 подростков и их матерей. Для исследования использовались 4 показателя латерального профиля: 
переплетение пальцев рук, скрещение рук на груди («поза Наполеона»), прицеливание (выявление доминантного глаза) и аплодирование (нахождение активной руки).

Исследования показали, что в нашей выборке мать с ребенком имеют

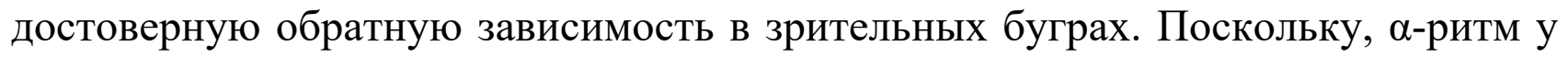
новорожденных отсутствует и, учитывая данные, полученные нами, о связи между мамой и ребенком в зоне зрительных бугров, можно предположить, что ребенок бессознательно подстраивает свой таламический водитель $\alpha$-ритма под материнский $\alpha$-ритм, компенсаторно ориентируясь на поддержание сенсорных импульсов матери, таким образом формируется со-стояние пары «матьмладенец». У детей с патологией зрения контакт с матерью происходит через сомато-сенсорные пути, которые также замыкаются в таламусе. Исходя из этого, мы можем предположить, что в первые три месяца идет настройка взаимодействия младенца с матерью не столько через взгляд и ее мимику, сколько через некую резонансную со-настройку мозга ребенка с мозгом матери посредством $\alpha$ - ритма. Этот период можно назвать «четвертым триместром беременности».

Выводы и перспективы дальнейших исследований. Пробы по определению ведущего глаза у матерей и их детей показали значимую отрицательную корреляцию, что подтверждает различие в латерализации, локализованной в таламусе, где расположены «зрительные бугры». Ребенок бессознательно подстраивает свой таламический водитель $\alpha$-ритма под материнский $\alpha$-ритм, компенсаторно ориентируясь на поддержание сенсорных импульсов матери. Возможно, что в состоянии стойкой реакции гиперактивации коры (hyperarousal), «левополушарная» мама, чтобы заглушить тревогу, может полностью «отключить» сигналы (просьбы о помощи) которые посылает ей ее «правополушарный» ребенок. Тем самым она, пытаясь отсоединить передачу 
идущей от ребенка противоречащей еe стилю мышления «опасной» информации, вызывает дефициты в его развитии. Несовпадение функциональной асимметрии мозговых структур участников взаимодействия пары «мать-ребенок», в случае зрелой личности мамы, создает «нормальную» привязанность через анатомический и психологический баланс.

Таким образом, конфликт разных стилей мышления мамы и ребенка заложен на глубинном уровне, что может быть одним из условий обеспечения эволюционного развития человека.

\section{Annotation}

Grigoryeva S. V., PhD in Medical Psychology, Psychotherapist, Deputy Head of the Psychoanalysis Section, Specialist in Psychoanalytic Psychotherapy, Children's Psychotherapist; Center for Family Neurocorrection and Psychotherapy, Odessa, Ukraine. Study of Brain Asymmetry and the Interaction of Brain Structures in the Mother-Child Dyad.

Keywords: mother-child dyad, asymmetry with lateral correlation, attachment, functional specialization of the hemispheres, visual cusps, $\alpha$-rhythm, postpartum stress, developmental pathology, postural asymmetry.

Formulation of the problem. The study of brain asymmetry in the motherchild dyad, within the framework of the theory of attachment, is necessary and relevant, since the first trimester is morpho-forming for the development of the child.

The relevance of research. We were interested in whether there is a connection between the asymmetry parameters of brain structures in the mother-child dyad, and how these parameters (laterality) are distributed in the child-mother pair.

Analysis of recent research and publications. Researchers of mother-child attachment models pay great attention to mother's facial expressions, as one of the main objects that form the baby's brain-body system. 
Formulating the purpose of the article. The purpose of the study is to determine the role of asymmetry of the brain structures of mother and child in the formation of pathological or normal attachment.

The presentation of the main material. The study examined lateral brain asymmetry indicators of 312 adolescents and their mothers. For the study, we used 4 indicators of the lateral profile: the interlacing of the fingers, the crossing of the arms on the chest ("Napoleon's pose"), aiming (revealing the dominant eye) and applause (finding the active arm).

Studies have shown that mother and child have a significant inverse relationship in the visual tubercles. The child unconsciously adjusts its thalamic $\alpha$ rhythm driver to the maternal $\alpha$-rhythm, compensatory focusing on maintaining the mother's sensory impulses. In children with visual pathology, contact with the mother occurs through somato-sensory pathways, which also close in the thalamus. Probably, in the first three months, the interaction between the infant and the mother is set up not so much through her eyes and her facial expressions as through the resonant mutual tuning of the child's brain with the mother's brain through the $\alpha$-rhythm. This period can be called the "fourth trimester of pregnancy."

Conclusions and prospects for further research. The child unconsciously adjusts its thalamic $\alpha$-rhythm driver to the maternal $\alpha$-rhythm, compensatory focusing on maintaining the mother's sensory impulses. It is possible that in the state of a persistent reaction of hyperarousal cortex, the "left hemisphere" mother, trying to disconnect the transmission of "dangerous" information coming from her child, which contradicts her thinking style, causes deficiencies in her development. The mismatch of the functional asymmetry of the brain structures of the mother and child, in the case of a mature mother's personality, creates a "normal" attachment through anatomical and psychological balance. 
Thus, the conflict of different styles of thinking of mother and child is laid at a deep level. This may be one of the conditions for ensuring the evolutionary development of man.

Ключевые слова: диада «мать-ребенок», асимметрия с соотнесением латеральности, привязанность, функциональная специализация полушарий, зрительные бугры, $\alpha$-ритм, послеродовый стресс, патология развития, позная асимметрия.

Постановка проблемы. Исследование асимметрии мозга в диаде «матьребенок» в рамках теории привязанности являются необходимыми и актуальными, поскольку для развития ребенка первый триместр является морфо-образующим.

Актуальность исследования. Наблюдая в практике, что совпадение или несовпадение параметров асимметрии мозговых структур участников взаимодействия является важным фактором во взаимопонимании между людьми, мы заинтересовались, может ли это оказывать влияние на «нормальную» семейную привязанность матери и ребенка, и решили исследовать это через физиологические показатели. Нас интересовало, существует ли связь между параметрами асимметрии мозговых структур в диаде «мать-ребенок», и как распределяются эти параметры (латеральность) в паре «ребенок-мать».

Анализ последних исследований и публикаций. Представим краткий теоретический анализ исследований как в области асимметрии центральной нервной системы (ЦНС), так и в области отношений, привязанности.

Джон Боулби говорит, что привязанность есть семейные узы, которые формируются в детстве и являются эмоциональной основой всей жизни. Мать и 
младенец входят в некую саморегулирующуюся систему, части которой взаимообусловлены. Система привязанности представляет собой первичную, генетически закрепленную мотивационную систему, которая активируется сразу после его рождения между первичным значимым лицом и младенцем, обеспечивая функцию выживания [1, с. 36].

Исследователи моделей привязанности «мать-ребенок» уделяют большое внимания мимике матери как одному из основных объектов, формирующих систему «мозг-тело» младенца. Они отмечают, что часто восприятие эмоций на материнском лице генерирует резонансное эмоциональное состояние у ребенка. Поиск близости происходит через визуальный контакт с матерью, но особенно путем следования за матерью и установления телесного контакта с ней [1, с. 37].

Внимание ученых в исследовании асимметрии ЦНС детей и родителей было в основном, направлено на выявления наследственных факторов леворукости (Д. Леви и Т. Нагилаки) [2]. Ли Солк научно описал феномен яркого проявления асимметрии в социальном поведении человека, как предпочтение держать ребенка с левой стороны от себя [7]. Им было обнаружено достоверное влияние эмоционального состояния матери на асимметричное расположение ребенка. Оказалось, что женщины, страдающие послеродовой депрессией, не проявляют левостороннего предпочтения [7].

Много исследований также проводится в области регуляции чувств через привязанность в отношениях. Алан Шор разработал детальную схему, связывающую когнитивные, эмоциональные, телесные стадии развития с радикальными изменениями в организации мозга. Оказалось, что сенсорная информация извне в иерархическом порядке обрабатывается лимбическими и кортикальными отделами мозга, что влияет на автономную нервную систему. Описывая привязанность младенца, он фокусировался на амигдале, поясной извилине и орбито-фронтальной коре. Каждый из этих отделов выступает как 
самостоятельная функциональная система и как зона для объединения информации. При нарушении привязанности отмечается торможение развития правого полушария, уменьшение объема гиппокампа, мозолистого и миндалевидного тела, а также не происходит созревание орбито-фронтальной коры [5].

Термин «латеральность» (лат. laterālis «боковой») нами используется в значении асимметрии как неполной идентичности левой и правой половин тела. Латеральность может проявляться на анатомическом, биохимическом, физиологическом и функциональном уровнях [2].

Формулировка цели статьи. Цель исследования - определить роль асимметрии мозговых структур мамы и ребенка в формировании патологической или нормальной привязанности.

Задачи исследования: выяснить, существует ли связь между мозговыми структурами участников взаимодействия в диаде «мама-ребенок» Мы предположили, что параметры функциональной асимметрии мозга ребенка и матери могут быть зеркально-симметричными, что возможно создает особое взаимодействие в паре.

Изложение основного материала. В исследовании изучались латеральные показатели позной асимметрии мозга 312 подростков и их матерей (переплетение пальцев рук, скрещение рук на груди, прицеливание и аплодирование).

Объект исследования: взаимоотношения в диаде «мать-ребенок».

Предмет исследования: влияние латеральности на качество взаимоотношений в диаде «мать-ребенок».

Методы исследования. Связь между структурами мозга можно исследовать с помощью ЭЭГ. Для выяснения, как соотносится активность разных мозговых структур в паре, мы сопоставили латеральные показатели 
матери и ребенка, используя более простые, но достоверные тесты по определению позной асимметрии. Для исследования использовались 4 показателя латерального профиля: переплетение пальцев рук, скрещение рук на груди («поза Наполеона»), прицеливание (выявление доминантного глаза) и аплодирование (нахождение активной руки).

В нашем исследовании принимали участие 312 человек, это были ученики 8-10-х классов и их матери. Выбор возраста испытуемых обусловлен тем, что в 14-16 лет завершается развитие функциональной асимметрии отделов мозга. Нашей задачей было обозначить, не акцентируя внимание на личном профиле латеральности каждого из участников исследования, как в паре «мама-ребенок» строится взаимодействие активности различных мозговых структур.

Известно, что доминантность глаза связана с активностью противоположного «зрительного бугра» и/или таламуса, где осуществляется связь между корой, с одной стороны, и мозжечком и базальными ганглиями - с другой. В нем фильтруется информация, поступающая от всех рецепторов, он осуществляет ее предварительную обработку, и затем она направляется в различные области коры [9]. Переплетение пальцев рук и скрещивание рук на груди, также как и другие движения, возникают за счёт импульсов, идущих по длинным нервным волокнам из коры больших полушарий головного мозга. Они являются аксонами нейронов, расположенных в средней части прецентральной извилины [6]. Манера аплодирования тесно связана с доминантностью руки, как показатель существовавшей изначально асимметрии мозговых структур, не имеющих прямого отношения к манипулятивности рук. Латеральность аплодирования представлена как моторное проявление простых эмоциональноокрашенных движений, которые формируются в лимбико-диэнцефальных структурах ЦНС и являются звеньями функциональной межполушарной асимметрии гестационной доминанты [4, с. 150]. 
Первоначально в иследовании принимало участие 124 человека. Статистический анализ полученных результатов проводился с использованием коэффициента корреляции Пирсона. Были получены значимые результаты по пробам аплодирования и определения ведущего глаза. Результаты пробы по определению ведущего глаза у матерей и их детей показали высоко достоверную отрицательную корреляцию $\mathrm{r}=-0,352\left(\mathrm{r}_{\mathrm{kp}}=0,197\right.$, при $\left.\mathrm{p}>0,05\right)$, свидетельствующую о различии в латерализации, локализованой в таламусе. Также, обнаружена достоверная отрицательная корреляция по пробе аплодирования $\mathrm{r}=-0,22\left(\mathrm{r}_{\mathrm{kp}}=0,197\right.$, при $\left.\mathrm{p}>0,05\right)$, за которую отвечает лимбикодиэнцефальная область.

Мы продолжили исследование, расширив количество участников до 312 человек (156 пар). Так как оба исследуемых признака - дихотомические, нами были построены двухвходовые таблицы сопряжённости размера 2х2, что позволило провести более точный статистический анализ полученных результатов. По этим таблицам были рассчитаны следующие показатели степени значимости статистической связи:

1) chi $^{2}$-- коэффициент квадратичной сопряжённости хи-квадрат;

2) phi -- коэффициент контингенции Пирсона;

3) Q -- коэффициент ассоциации Юла;

4) С -- коэффициент коллигации Юла.

Результаты пробы по определению ведущего глаза у матерей и их детей показали значимую отрицательную корреляцию $\mathrm{chi}^{2}=3.88(\mathrm{p}>0,05)$, phi $=$ 0.17, $\mathrm{Q}=-0.34, \mathrm{C}=-0.17$, что подтверждает закономерное различие в латерализации, сфокусированной в таламусе, где расположены «зрительные» или «чувствительные бугры». По трём остальным параметрам (переплетение пальцев рук, скрещение рук на груди и нахождение активной руки при аплодировании) значимых корреляций не выявлено. Связь по аплодированию с 
увеличением выборки не подтвердилась. Обнаруженная обратная зависимость по пробе определения ведущего глаза означает, что связь очень сильная и не пропадает с увеличением выборки (рис.1).

Поэты говорят, что глаза - зеркало души. Нейропсихологи могут сказать точнее, что каждый из глаз - зеркало левого либо правого полушария мозга. Основным источником импульсации направляющейся в кору является зрительный бугор. Его ядра получают сигнал из большинства (кроме обонятельных), сенсорных систем, а также из базальных ядер, гиппокампа и мозжечка. Таким образом, в зрительном бугре сосредотачивается и перекодируется информация, поступающая с периферии в кору мозга [3, с. 386].

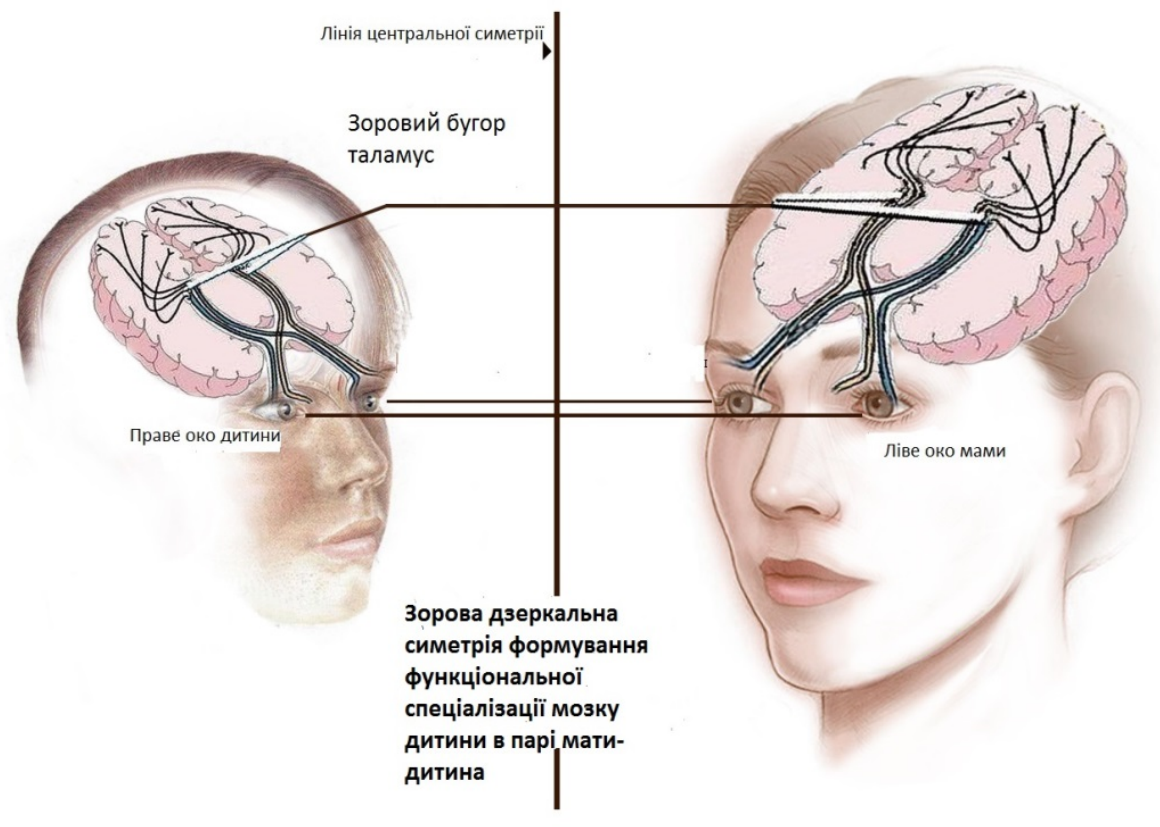

Рис.1. Зрительная зеркальная симметрия мозга ребенка относительно мозга матери.

Джерре Леви и ее коллеги определили, что два полушария различаются информацией, которую они извлекают из зрительных стимулов [2, с. 229]. 
Таким образом, доминантность в зоне зрительных бугров конкретного индивида определяет, какую именно часть информации способен извлечь этот человек из общего потока сенсорных стимулов. В данном контексте, наше исследование показало, что в случае несовпадения доминантности в зоне зрительных бугров у матери и ребенка, каждый из них извлекает из одинаковых сенсорных стимулов разную информацию. Левое полушарие специализируется на последовательной обработке информации и является более аналитическим и более символическим и вербальным из двух полушарий. В противоположность этому, области правого полушария хорошо справляются с одновременной обработкой различных видов информации, необходимых для восприятия пространственных паттернов и являются более невербальными. Левое полушарие воспринимает и анализирует элементы сложного зрительного объекта, а правое полушарие воспринимает его общую конфигурацию [3, с. 429].

Таким образом, мы можем сформулировать предположение, что в некоторых парах подросток (ребенок) отличается от своей матери диаметрально противоположным стилем «снятия» и обработки информации. Например, если у матери ведущее правое полушарие, то она: может одновременно обрабатывать много разнообразной информации, видит проблему в целом, запоминает образы, лица, чувствует эмоциональную окраску речи, интонацию, ориентируется в настоящем, умеет мечтать и фантазировать. Ее левополушарный ребенок, достигший подросткового возраста, будет анализировать факты, умеет планировать будущее, обрабатывать информацию последовательно, индуктивно мыслить.

Исследования показали, что в нашей выборке мать с ребенком имеют достоверную обратную зависимость в зрительных буграх. Известно, что $\alpha$-ритм формируется в коре под влиянием импульсов, исходящих из неспецифических ядер зрительного бугра и эти импульсные посылки генерируют таламические 
водители $\alpha$-ритма [3, с. 386]. Наибольшую амплитуду $\alpha$-ритм имеет в состоянии спокойного бодрствования, особенно при закрытых глазах в затемнённом помещении. Он блокируется или ослабляется при повышении внимания (в особенности зрительного) или мыслительной активности, а также в ситуации стресса, реакции hyperarousal, т.е. стойкой реакции гиперактивации коры. У матери в такие моменты наступает угнетение $\alpha$-ритма и десинхронизация нейронов коры. У новорожденного ребенка $\alpha$-ритм отсутствует и начинает проявляться слабыми импульсами только к 3-х месячному возрасту [3]. Нарушения ритмической последовательности $\alpha$-ритма у мамы в первые несколько месяцев после рождения ребенка могут нарушить формирование таламического синхронизирующего механизма у младенца, так как у ребенка не будет возможности найти $\alpha$-ритм матери и настроиться на него. Поскольку, $\alpha$ ритм у новорожденных отсутствует и, учитывая данные, полученные нами, о связи между мамой и ребенком в зоне зрительных бугров, можно предположить, что ребенок бессознательно подстраивает свой таламический водитель $\alpha$-ритма под материнский $\alpha$-ритм, компенсаторно ориентируясь на поддержание сенсорных импульсов матери, таким образом формируется состояние пары «мать-младенец». У детей с патологией зрения контакт с матерью происходит через сомато-сенсорные пути, которые также замыкаются в таламусе [6].

Исходя из этого, мы можем предположить, что в первые три месяца, идет настройка взаимодействия младенца с матерью не столько через взгляд и ее мимику, сколько через некую резонансную со-настройку мозга ребенка с мозгом матери посредством $\alpha$ - ритма. И мы могли бы этот период назвать «четвертым триместром беременности».

На сегодняшний день известно, что восприятие ребенком эмоций на материнском лице создает у него соответствующее эмоциональное состояние 
[1]. Однако, физиология младенца такова, что в первые месяцы цилиарные мышцы глаз остаются тонкими и слабыми, поэтому ребенку сложно сфокусировать взгляд на объектах, находящихся вблизи. Зрение новорожденного оценивается на уровне ощущения пятен света и тени. Фокусированное зрение появляется только на 2-3 месяце жизни младенца. Возможно, что резонанс (в диапазоне $\alpha$-ритма) можно осуществить через телесные, поведенческие и психофизиологические проявления мамы, которые способен воспринимать ребенок в этом возрасте (тембр голоса, интонацию, паттерны ритма движений тела мамы и т.д.).

Известно, что $\alpha$ - ритм у нас возникает в состоянии легкой дремы. Это тип электрической активности мозга, в котором лучше проявляются межполушарные взаимодействия, когда внимание человека переключается с внешнего мира на внутренний [1]. И, возможно, в первые три месяца после рождения ребенка, частое пребывание мамы в состоянии настроенности на восприятие внутреннего мира является продуктивным для развития мозга ребенка. А также, что послеродовая депрессия возникает часто из-за сложности переключения внимания мамы на правополушарный стиль мышления, при котором у мамы большая чувствительность, тонкое понимание младенца. Но делать это сознательно, левым мозгом, не получается. Физиологически возникает своеобразное отключение от внешней отвлекающей афферентации, при котором ребенок может получить максимальное мамино внимание и чувственность.

Современная жизнь ставит перед женщиной огромные социальные задачи (работа, общественная деятельность, активная позиция в социальных сетях), и порой ей очень хочется после родов быстро влиться в привычную до появления ребенка жизнь. Но послеродовая перестройка эмоционального состояния (проживание депрессии) для мамы может быть со временем успешно пережита 
и скомпенсирована, а для развития ребенка эти три месяца жизни являются морфо-образующими. Очень важно для мамы научиться общаться с младенцем спокойно, корректно настраиваться на его резонанс, ведь необходимость развития правого полушария невероятно велика, это фундамент и для надежной привязанности и для гармоничного развития личности. Однако, результаты исследования NICHD наглядно показали, что если уход за ребенком в первые 15 месяцев осуществляет не мама, а другой человек, это не дает основания для формирования ненадежной привязанности [1]. Видимо, у ухаживающих людей (не обязательно женщин) был хороший $\alpha$-ритм, который помог выстроить с ребенком надежную привязанность. Таким образом, выше мы описали структуру взаимодействия $\alpha$ - ритма мамы и таламического водителя $\alpha$-ритма ребенка в норме.

Теперь рассмотрим предположительную схему на уровне психофизиологического взаимодействия в паре «мама-ребенок», которая может формироваться в случаях, когда ребенок патологизируется в когнитивной сфере. Известно, что до двух-трех лет у ребенка активно действует и развивается в основном правое полушарие мозга. Шор считает, что это связано с тем, что именно правое полушарие отвечает за эмоции и привязанность с матерью и жизненно необходимо для выживания, а также известно, что в основе многих психических и психосоматических расстройств лежит функциональная неполноценность правого полушария [5]. У эмоционально зрелой и уравновешенной мамы, обладающей гибкостью мышления и межполушарного взаимодействия, есть возможность настраиваться на правополушарное мышление малыша. А если мама склонна вытеснять свою эмоциональную сферу, ей будет тяжелее построить общение с ребенком. В состоянии стойкой реакции hyperarousal, мозг взрослого человека включает стратегию контроля над правым полушарием, с блокированием сенсорной информации, 
поступающей оттуда.

Зная, что в периоде новорожденности, мама с ребенком находятся в состоянии омнипотентного единства, можно предположить, что у левополушарной матери могут включаться структуры защит, блокирующих переработку ее эмоций, когда ее ведущее левое полушарие берет под контроль сенсорные каналы правого полушария ребенка. Игнорирование эмоций, тревожность, критицизм матери в процессе взаимодействия с ребенком могут оказывать давление на младенца. Возможно, что в состоянии стресса левополушарная мама, для того чтобы заглушить свою тревогу и эмпатически не чувствуя ребенка, может полностью «отключить» сигналы (просьбы о помощи) которые посылает ей ее «правополушарный» ребенок. Тем самым она пытается отсоединить передачу идущей от ребенка, противоречащей ее стилю мышления «опасной» информации. Это формирует в дальнейшем дефициты в развитии ребенка. Потому что такая стратегия мамы как бы оставляет младенца в ее воображаемом пространстве, ограничивая ребенка в возможности получать свой собственный опыт реалистического переживания себя. Не все подобные состояния приводят к патологии мышления, но они формируют пробелы, нехватку в развитии личности. Мы предполагаем, что во взрослом состоянии человеку можно частично компенсировать эту нехватку, сознательно переводя свое активное внимание на сенсорные каналы, самоощущения, учась осознанно слышать, ощущать и чувствовать.

Доктор Ральф-Аксель Мюллер, в процессе исследования более 50 детей с аутизмом, проводил комбинированные техники функциональной и анатомической магнитно-резонансной томографии и диффузионную тензорную визуализацию для анализа связей между корой головного мозга и таламусом. Он обнаружил, что у таких детей есть нарушения в проводящих путях между таламусом и корой головного мозга, а значит, эти отделы мозга плохо 
сообщаются друг с другом [2]. Напомним, что таламус играет роль перерабатывающего, интегрирующего и переключающего центра для всей сенсорной информации. Эти исследования подтверждают наше предположение, высказанное выше, о возможном блокировании мамой развития сенсорных каналов ребенка. В нашей практике данное предположение косвенно подтверждается тем, что некоторые мамы, воспитывающие ребенка с нарушениями когнитивного развития, отмечают свои пережитые психологические травмы во время беременности и после родов (тяжелые болезни или смерть близкого человека). Конечно, аутизм - это болезнь, которая рассматривается на системном уровне, как структурная и функциональная проблема вовлечения разных областей мозга в информационный процесс коммуникации друг с другом. В ней нет единого повреждения части мозга и значительная доля случаев этой болезни связана с нарушениями в индивидуальном развитии ребёнка, которые происходят ещё на эмбриональной стадии. Но можно заметить, что у них есть что-то общее - своей специфической игрой, дети с аутизмом создают зацикленные алгоритмы, нагружая левое полушарие и оставляя правое отключенным. Возможно, так они пытаются следовать за маминым доминантным полушарием.

Социальная жизнь требует от мамы активного включения бета-ритма, ритма активации нейрофункциональной активности. Маме хочется поскорее построить взаимодействие с ребенком в привычном ей стиле, с выполнением аналитических задач и работой по определенным алгоритмам. Наш опыт работы c матерями, воспитывающими ребенка с аутизмом, показывает, что большинство их обладают левополушарной структурой мышления, которая выражается в аксиоме - «есть только мое мнение и неправильное». Настроится же на правополушарное, образно-чувственное мышление, мамам с негибкими межполушарными связями бывает очень нелегко, а часто они в этом не видят 
смысла. Умение развить свои межполушарные связи самостоятельно или в терапии показывает, насколько целительной для них становится возможность соприкоснуться с правополушарным подходом. С начала прошлого века женщина активно включилась в производственные отношения, доминируя во многих позициях, так как, в среднем, левое полушарие у женщин развивается лучше, чем у мужчин [3]. Иногда приоритет социальной успешности женщины, в противовес материнской функции, формирует условия, вызывающие игнорирование матерью ее великой женской миссии. Но природа настойчиво сохраняет свои законы развития, которые недопустимо нарушать. Важность правого полушария в жизни людей огромна. Подготовка к беременности должна бать, в первую очередь, направлена на внимание к чувствам и сенсорному насыщению. Необходимо уделять внимание занятиям живописью, музыкой, рукоделием, душевным разговорам о счастье и тихой радости.

Далее рассмотрим, какое практическое значение знания о противоположном (зеркально-симметричном в паре) доминировании зрительных бугров в диаде «мама-ребенок» мы можем иметь в социальнобытовом контексте, в поведении и взаимодействии. Например, мама, обладающая доминантным левым полушарием, склонна иметь дело с быстрыми изменениями во времени и анализировать стимулы с точки зрения деталей и признаков, действуя аналитическим способом. Она умеет планировать новые дела во всех подробностях, действовать логически, не делая поспешных выводов, редко мечтает наяву, всегда старается найти причину каждого поступка других людей, пунктуальна, обладает хорошим чувством времени, может описывать свои чувства словами и, полагаясь на очевидное, принимать решения. В противоположность ей, ребенок, имея доминантное правое полушарие, склонен взаимодействовать с миром в образной, синтетической манере, делать дела спонтанно, приходить к выводам без последовательного 
обдумывания всех деталей и аргументации. Он может мечтать наяву и видеть яркие сны, редко задумываться над поступками других людей, имеет плохо развитое чувство времени, трудности при описании словами своих чувств, но при этом, при принятии решений, полагается именно на чувства [2, с. 120]. И в случае, если ребенок не получил опыт принятия, понимания и точного чувственного отражения, это различие может вызывать семейные конфликты.

Таким образом, на глубоком анатомическом уровне в паре «мамаребенок» формируется соотнесенное функционирование специальных мозговых структур, проявляющееся, как системообразующее взаимодействие, часто воспринимаемое как конфликт. Исходя из комплекса описанных исследований, можно сделать вывод, что основной функцией системы «мама-ребенок» является создание баланса во взаимодействии друг другом и с окружающей средой. Как будут проявляться взаимоотношения в паре, в виде баланса или конфликта будет зависеть от того, насколько зрелой личностью является мама (насколько она способна воспринимать кардинально другой способ взаимодействия с миром, осуществляемый ее ребенком). В психологической терминологии сбалансированные отношения описываются как «нормальная» привязанность.

Симоненко В. Е., исследуя семейные и дружеские пары, пришел к заключению, что среди супругов совпадение латеральности составляет 83\% [4, c. 75]. Логично предположить, что позитивной функцией латерального конфликта в паре «мама-ребенок», может быть облегчение сепарации в процессе взросления ребенка и создание новых отношений вне родительской семьи. Таким образом, одним из важных аспектов философии жизни может быть обеспечение баланса внутри этого конфликта. Более того, если при некоторых обстоятельствах, конфликт «мать-ребенок» отсутствует, система 
может испытывать затруднения. Слияние в паре может вызвать сложность при формировании идентичности и личного пространства для развития.

Выводы. Пробы по определению ведущего глаза у матерей и их детей показали значимую отрицательную корреляцию, что подтверждает различие в латерализации, локализованной в таламусе, где расположены «зрительные бугры». В случае несовпадения доминантности в этой зоне, каждый из пары извлекает из одинаковых сенсорных стимулов разную информацию и мыслит по-разному. Ребенок бессознательно подстраивает свой таламический водитель $\alpha$-ритма под материнский $\alpha$-ритм, компенсаторно ориентируясь на поддержание сенсорных импульсов матери. Возможно, что в состоянии стойкой реакции гиперактивации коры (hyperarousal), левополушарная мама, чтобы заглушить тревогу, может полностью «отключить» сигналы (просьбы о помощи) которые посылает ей ее «правополушарный» ребенок. Тем самым она, пытаясь отсоединить передачу идущей от ребенка противоречащей ее стилю мышления «опасной» информации, вызывает дефициты в его развитии. Несовпадение функциональной асимметрии мозговых структур участников взаимодействия пары «мать-ребенок», в случае зрелой личности мамы, создает «нормальную» привязанность через анатомический и психологический баланс.

Мы показали, что конфликт разных стилей мышления мамы и ребенка заложен на глубинном уровне, и предположили, что это может быть одним из условий обеспечения эволюционного развития человека.

\section{Список використаних джерел:}

1. Бріш К. Х. Терапія порушень прихильності: Від теорі\до практики / К.X. Бріш.- М.: ІП РАН «Когіто-Центр», 2012.- 316 с.

2. Спрінгер С. Лівий мозок, правий мозок / С. Спрінгер, Г. Дейч.- М.: Мир, 1983.- 182 c. 
3. Хасабов Г.А. Короткий довідник з фізіології нервової системи / Г.А. Хасабов.- Луганськ: ООО «Віртуальна реальність», 2007.- 452 с.

4. Чуприков А. П. Латеральність населення наприкінці 70-х і на початку 80х років. До історії латеральної нейропсихології та нейропсихіатрії / А. П. Чуприков, В. Д. Мишиєв.- Донецьк: Вид.Заславський Ю. А., 2010.- 192 с.

5. Нік Тоттон (Nick Totton). Тристороння модель регуляції Алана Шора. Режим доступу: https://www.google.com.ua/search?q=\%D0\%B0\%D0\%BB\% D0\%B0\%D0\%BD+\%D1\%88\%D0\%BE\%D1\%80+\%D0\%BA\%D0\%BD\%D0\%B8\% D0\%B3\%D0\%B8\&oq=\%D0\%90\%D0\%BB $\%$ D0\%B0\%D0\%BD+\&aqs=chrome.4.69i 57j013j35i39j0.6267j0j8\&sourceid $=$ chrome\&ie $=U T F-8 \#$

6. Bryan Kolb. Fundamentals of Human Neuropsychology / Bryan Kolb, Ian Q. Whishaw. - Worth Publishers, New York, 2015. - 873 p.

7. Sieratzki J. S. Neuropsychological and neuropsychiatric perspectives on maternal cradling preferences / Sieratzki J. S., Woll B. // Epidem. Psichiatr. Soc. 2002. V. 11. P. 170-176.

8. S. Murray Sherman, Ray W. Guillery. Exploring the Thalamus: [англ.]. - 1-e изд.- Academic Press, 2000.- 312 c.

\section{References}

1. Brish, K.H. (2012), Terapiya narushenij privyazannosti: Ot teorii k praktike [Therapy of attachment disorders: From theory to practice], "Kogito-Centr",Moscow, $\mathrm{Ru}$.

2. Springer, S. Dejch, G. (1983), Levyj mozg, pravyj mozg [Left brain, right brain], - Mir, Moscow, Ru.

3. Hasabov, G. A. (2007), Kratkij spravochnik po fiziologii nervnoj sistemy [A short guide to the physiology of the nervous system], OOO «Virtualnaya realnost», Lugansk, Ru. 
4. Chuprikov, A. P. Mishiev, V.D. (2010), Lateralnost naseleniya v konce 70-h $i$ nachale 80-h godov. K istorii lateralnoj nejropsihologii i nejropsihiatrii [Laterality of the population in the late 70 's and early 80 's. To the history of lateral neuropsychology and neuropsychiatry], Izdatel Zaslavskij Yu.A., Doneck, Ru.

5. Totton, N. Alan Shore's three-way regulation model [Online], available at: https://www.google.com.ua/search?q=\%D0\%B0\%D0\%BB $\% \mathrm{D} 0 \% \mathrm{~B} 0 \% \mathrm{D} 0 \% \mathrm{BD}+\% \mathrm{D}$ 1\%88\%D0\%BE\%D1\%80+\%D0\%BA\%D0\%BD\%D0\%B8\%D0\%B3\%D0\%B8\&oq= $\% \mathrm{D} 0 \% 90 \% \mathrm{D} 0 \% \mathrm{BB} \% \mathrm{D} 0 \% \mathrm{~B} 0 \% \mathrm{D} 0 \% \mathrm{BD}+\& \mathrm{aqs}=\mathrm{chrome} .4 .69 \mathrm{i} 57 \mathrm{j} 013 \mathrm{j} 35 \mathrm{i} 39 \mathrm{j} 0.6267 \mathrm{j} 0 \mathrm{j}$ $8 \&$ sourceid $=$ chrome $\&$ ie $=$ UTF- $8 \#$

6. Kolb, B. Whishaw, Ian Q. (2015), Fundamentals of Human Neuropsychology, Worth Publishers, New York, En.

7. Sieratzki, J. S. Woll, B. (2002), "Neuropsychological and neuropsychiatric perspectives on maternal cradling preferences", Epidem. Psichiatr. Soc, vol. 11, pp. 170-176, En.

8. Sherman, Murray S. Guillery, Ray W. (2000), “Exploring the Thalamus@, Academic Press, En. 